\title{
Controversial Impact of Hepcidin Metabolism in the Pathogenesis of Anemia in Myelofibrosis
}

\author{
Stela Dimitrova ${ }^{1,}{ }^{*}$, Liana Gercheva $^{1}$, Daniela Gerova ${ }^{2}$, Ilina Micheva ${ }^{1}$ \\ ${ }^{1}$ Clinic of Hematology, UMHAT "Sveta Marina”, Medical University, Varna, Bulgaria \\ ${ }^{2}$ Laboratory of Immunology, UMHAT “Sveta Marina”, Medical University, Varna, Bulgaria
}

Email address:

stelladimitrova@abv.bg (S. Dimitrova)

${ }^{*}$ Corresponding author

To cite this article:

Stela Dimitrova, Liana Gercheva, Daniela Gerova, Ilina Micheva. Controversial Impact of Hepcidin Metabolism in the Pathogenesis of Anemia in Myelofibrosis. American Journal of Internal Medicine. Vol. 8, No. 4, 2020, pp. 153-158. doi: 10.11648/j.ajim.20200804.13

Received: May 22, 2020; Accepted: June 18, 2020; Published: July 6, 2020

\begin{abstract}
Anemia in myelofibrosis (MF) is a result of a multifactorial process, which is incompletely understood. The central pathogenetic mechanism is a replacement of normal hemopoietic tissue by fibrotic stroma. However, ineffective erythropoiesis, inflammation and iron overload have an additional impact on anemia development, suggesting the role of dysregulated iron homeostasis and hepcidin. The aim of the study was to analyze parameters of iron metabolism and inflammation in patients with different forms and stages of myelofibrosis. Thirty-six patients with primary MF, post-polycythemia vera and post-essential thrombocythemia MF and fourteen healthy controls were included in the study. In the patient group, serum ferritin, Fe, TIBC and parameters of $\mathrm{CBC}$ were measured as a part of routine clinical assessment. Plasma total hepcidin levels and concentrations of Interleukin-6 (IL6) and Interleukin-8 (IL8) were measured in duplicate by ELISA (My BioSource, San Diego, USA) in patients and healthy controls. The hepcidin level in the patient group was found statistically lower compared to healthy controls $(27,64 \pm 41,56 \mathrm{ng} / \mathrm{ml} ; 111,13 \pm 49,56 \mathrm{ng} / \mathrm{ml} ; \mathrm{F}=2,81, \mathrm{p}<0,001)$. Patients with newly diagnosed MF had significantly higher levels of hepcidin compared to those with prolonged evolution: between 1 and 5 years $(p=0,005)$ and $>5$ years $(p=0,038)$. Transfusion dependent patients presented with lower hepcidin compared to transfusions independent $(10,10 \pm 6,67 \mathrm{ng} / \mathrm{ml} ; 31,15 \pm 44,37 \mathrm{ng} / \mathrm{ml}$; $\mathrm{p}=0,026)$. In patients receiving cytoreductive or target treatment hepcidin level was significantly lower compared to patients on best supportive care $(17,74 \pm 21,99 \mathrm{ng} / \mathrm{ml} ; 43,05 \pm 58,46 \mathrm{ng} / \mathrm{ml} ; \mathrm{p}=0,037)$. No difference was found in hepcidin level within the risk groups according to DIPSS, neither between the subtypes of disease (primary MF and secondary MF). Higher hepcidin positively correlated with leukocytosis $(\mathrm{R}=0,665, \mathrm{p}=0,009)$ and age $(\mathrm{R}=0,392, \mathrm{p}=0,0081)$. By multivariate analysis, a significant highly positive correlation was found between hepcidin and IL- $6(\mathrm{R}=0,535, \mathrm{p}=0,002)$ and weaker between hepcidin and IL- $8(\mathrm{R}=0,413$, $p=0,21)$ A significant straight correlation was demonstrated between IL- 6 and IL-8 $(R=0,464, p=0,009)$ and a negative between serum iron and IL-6 $(\mathrm{R}=-0,367, \mathrm{p}=0,42)$ and IL-8 $(\mathrm{R}=-0,438, \mathrm{p}=0,14)$, respectively. The hepcidin regulation is complex and multifactorial. Its role in pathogenesis of anemia in myelofibrosis is controversary. Probably it has a higher impact in early stages of the disease and depends on treatment and transfusions.
\end{abstract}

Keywords: Myelofibrosis, Hepcidin, Anemia, Inflammatory Cytokines

\section{Introduction}

Myelofibrosis (MF) is a stem cell disorder characterized with impaired hematopoiesis and complex pathogenesis. Patients with MF often develop anemia and frequently become dependent on red blood cell transfusions (RBC) [1].

Anemia in MF is a result of a multifactorial process, which is incompletely understood. The central pathogenetic mechanism is replacement of normal hemopoietic tissue by fibrotic stroma [2]. However, the ineffective erythropoiesis, inflammation and iron overload have an additional impact on development and worsening of the anemia, suggesting the role of dysregulated iron homeostasis and hepcidin.

Hepcidin is a principal iron-regulatory hormone that mediates the homeostasis of extracellular iron concentrations through iron influx into plasma from tissues engaged in iron storage or transport [3]. It is increased in response to 
increased body iron levels, transferrin saturation or inflammation, and is decreased in response to hypoxia, erythropoietic activity and oxidative stress [4]. Its bioactive form, a 25-amino acid peptide can be detected circulating in plasma and excreted in urine.

Hepcidin level was found elevated in patients with many cancers, multiple myeloma and non-Hodgkin lymphomas [5]. Dysregulation of hepcidin synthesis is associated with anemia in three conditions: iron refractory iron deficiency anemia (IRIDA), the common anemia of acute and chronic inflammatory disorders, and the extremely rare hepcidinproducing adenomas that may develop in the liver of children with an inborn error of glucose metabolism. Inappropriately high levels of hepcidin cause iron-restricted or even irondeficient erythropoiesis in all these conditions [6].

Dysregulation of several inflammatory pathways in malignant cells like bone morphogenic protein (BMP) and interleukin-6 (IL-6) contributed to the dysregulation of hepcidin expression [7-9]. Inflammatory cytokines also exert a number of other hepcidin-independent effects on iron homeostasis at multiple levels, including increasing macrophage iron uptake, increasing erythrophagocytosis, and promoting efficient iron storage [10-13].

Recently, it has been demonstrated that the elevated hepcidin levels in newly diagnosed patients with MF were associated with hemoglobin levels $<10 \mathrm{~g} / \mathrm{dL}$, increased requirement for $\mathrm{RBC}$ transfusions, higher ferritin level and reduced survival independently of DIPSS (Dynamic International Prognostic Scoring System) [14]. It would be of interest to clarify the role of dysregulated iron homeostasis through the course of the disease in the context of treatment and disease evolution.

The aim of the study was to analyze parameters of iron metabolism and inflammation in patients with different forms and stages of myelofibrosis.

\section{Materials and Methods}

Patients with primary, post-polycythemia vera (PV) and post-essential thrombocythemia (ET) MF were considered eligible for participation in the study. The diagnosis of MF was established according to the World Health Organization criteria [15]. DIPSS was used for risk stratification. [16] All patients and 14 healthy controls signed an informed consent for participation in the study and peripheral blood collection. The study was approved by the local Ethical Committee. Peripheral blood was drawn following standard procedures for isolation plasma and storage aliquots at $-80^{\circ} \mathrm{C}$. Serum total hepcidin-25 level and serum concentrations of IL- 6 and interleukin-8 (IL-8) were measured in duplicate by ELISA (My BioSource, San Diego, USA) as per the manufacturer's instructions. Samples were diluted 50- to 100-fold and all measurements were done on MIT511-4 Microplate reader. The results were valued by using MikroWin v. 4.31 (Mikrotek Laborsysteme GmbH, Germany) software.

Serum ferritin, serum iron (Fe), total iron-binding capacity (TIBC) and parameters of complete blood count (CBC) were measured as a part of routine clinical assessment.

Strength and direction of linear relationships between continuous variables were measured by multivariate correlation analysis. Statistical differences among means of two or more independent groups were analyzed by one Sample $t$-Test for a single comparison and one-way ANOVA test for multiple comparisons. Linear regression analysis with establishing a ROC curve was used to model the relationship between an independent and one or more dependent variables. $\mathrm{P}$-values of $<0,05$ were considered significant. SPSS version 19 was used for all calculations.

\section{Patients' Characteristics}

Thirty-six patients with MF - 75\% (n=27) with primary MF (PMF) and 25\% (n=9) with secondary MF (post-PV $11,1 \%(n=4)$ and post-ET - 13,9\% $(n=5))$ were analyzed. Median age of the group was 68,5 years (range 39-88); male: female ratio- 1,57:1. All patients were divided in 3 groups according to the time from diagnosis: newly diagnosed $(30,6 \%, n=11), 1$ to 5 years $(47,2 \%, n=17)$ and $>5$ years $(22,2 \%, \mathrm{n}=8)$ from diagnosis. According to DIPSS: $5,6 \%$ $(\mathrm{n}=2)$ were low; $52,8 \%(\mathrm{n}=19)$ were intermediate $1 ; 33,3 \%$ $(n=12)$ were intermediate 2 and $8,3 \%(n=3)$ were high risk. Regarding treatment, $30,6 \%(n=10)$ of the patients received hydroxyurea, 8,3\% (n=4) - Interferon $\alpha, 19,4 \%(n=7)$ Ruxolitinib and $41,7 \%(\mathrm{n}=15)$ - best supportive care (BSC). Regarding blood transfusions the patients were divided in transfusion independent - 80,5\% $(n=30)$ and transfusion dependent (classified as patients receiving $\geq 3 \quad \mathrm{RBC}$ units/month) - 19,5\% $(n=6)$.

\section{Results}

The hepcidin level in the patient group was found statistically lower compared to healthy controls $(27,64 \pm 41,56$ $\mathrm{ng} / \mathrm{ml} ; 111,13 \pm 49,56 \mathrm{ng} / \mathrm{ml} ; \mathrm{F}=2,81, \mathrm{p}<0,001$ ) (Figure 1).

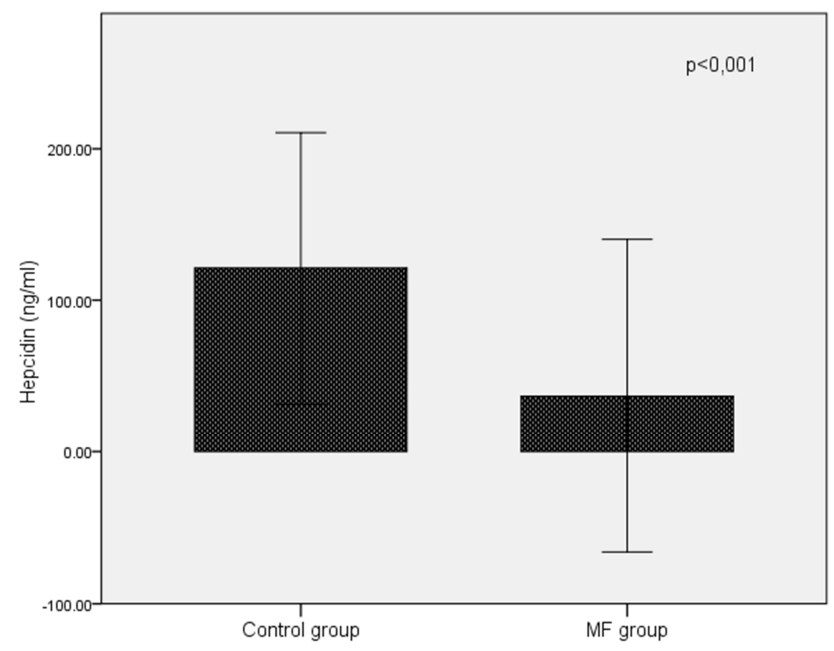

Figure 1. Hepcidin levels in MF patients compared to control group. Box plot representation shows higher hepcidin levels $(\mathrm{ng} / \mathrm{ml})$ in the control group compared to the MF patients $(p<0,001)$. 
The difference remained statistically significant when controls were compared to the three different subgroups according to disease duration: less than 1 year $(61,21 \pm 62,57$ $\mathrm{ng} / \mathrm{ml}, \mathrm{t}=2,23, \mathrm{p}=0,036)$; between 1 and 5 years $(13,75 \pm 11,80$ $\mathrm{ng} / \mathrm{ml}, \mathrm{t}=7,86, \mathrm{p}<0,001)$; more than 5 years $(11,00 \pm 6,02$ $\mathrm{ng} / \mathrm{ml}, \mathrm{t}=5,63, \mathrm{p}<0,001)$ from disease onset.

Patients with newly diagnosed MF $<1$ year from the disease onset as well had significantly higher levels of hepcidin compared to those with prolonged evolution: between 1 and 5 years $(t=3,07, p=0,005)$ and $>5$ years $(\mathrm{t}=2,25, \mathrm{p}=0,038)$ (Figure 2).

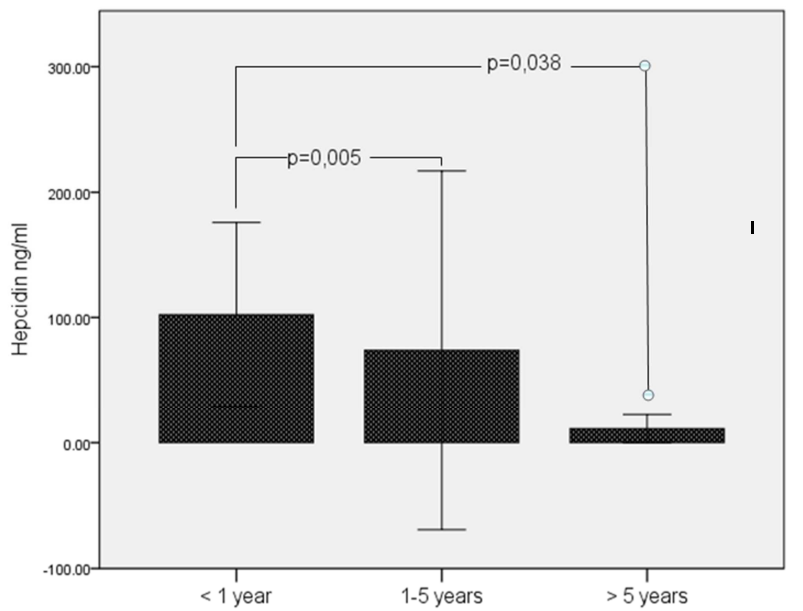

Figure 2. Hepcidin levels in MF patients stratified by disease duration. Box plot representation shows higher hepcidin levels $(\mathrm{ng} / \mathrm{ml})$ in newly diagnosed patients compared to those with prolonged disease evolution $(p=0,003)$.

Transfusion dependent patients presented with lower hepcidin compared to transfusion independent $(10,10 \pm 6,67$ $\mathrm{ng} / \mathrm{ml} ; 31,15 \pm 44,37 \mathrm{ng} / \mathrm{ml} ; \mathrm{p}=0,026$ ) (Figure 3).

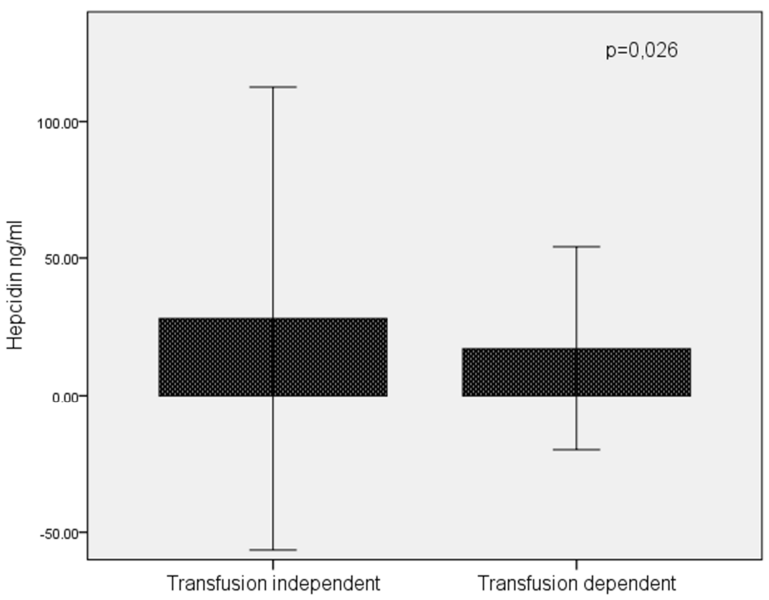

Figure 3. Hepcidin levels in MF patients stratified by blood transfusion dependence. Box plot representation shows lower hepcidin levels $(\mathrm{ng} / \mathrm{ml})$ in poly-transfused patients ( $>3$ units/month) $(p=0,026)$.

In patients receiving cytoreductive or target treatment hepcidin level was significantly lower compared to patients on BSC $(17,74 \pm 21,99 \mathrm{ng} / \mathrm{ml} ; 43,05 \pm 58,46 \mathrm{ng} / \mathrm{ml} ; \mathrm{p}=0,037)$ (Figure 4).

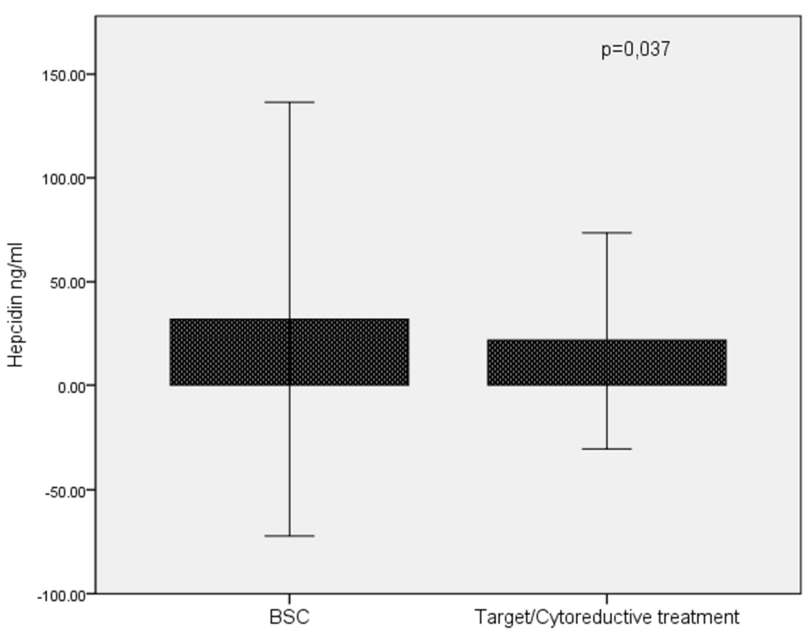

Figure 4. Hepcidin level in MF patients stratified by treatment approach. Box plot representation shows lower hepcidin levels $(\mathrm{ng} / \mathrm{ml})$ in patients, receiving target/cytoreductive therapy $(p=0,037)$.

No difference was found in hepcidin level within the risk groups according to DIPSS, neither between the subtypes of disease (PMF and secondary MF). We found that higher hepcidin (cutoff for intermediate 2 and high risk $>13,615$ $\mathrm{ng} / \mathrm{ml}$; cut off for Intermediate risk $1>13,14 \mathrm{ng} / \mathrm{ml}$ ) positively correlated with leukocytosis $(\mathrm{R}=0,665, \mathrm{p}=0,009)$ and age $(\mathrm{R}=0,392, \mathrm{p}=0,0081)$.

Higher level of ferritin (cutoff for intermediate $1>424,5$ $\mu \mathrm{g} / \mathrm{l}$, intermediate $2>460,45 \mu \mathrm{g} / \mathrm{l}$, high $>355,15 \mu \mathrm{g} / \mathrm{l})$ was associated with high serum iron $(\mathrm{R}=0,621, \mathrm{p}<0,001)$ and low hepcidin $(\mathrm{R}=-0,225, \mathrm{p}=0,023)$.

The levels of IL-6 and IL-8 in the MF group were not found statistically different compared to the control group $(11,91 \pm 26,31 \mathrm{pg} / \mathrm{ml} ; 15,90 \pm 26,64 \mathrm{pg} / \mathrm{ml} ; \mathrm{F}=0,771, \mathrm{p}=0,720$ and $134,89 \pm 175,93 \mathrm{pg} / \mathrm{ml} ; 127,22 \pm 183,12 \mathrm{pg} / \mathrm{ml} ; \mathrm{F}=1,097$, $\mathrm{p}=0,414$, respectively). No significant difference was found in the levels of IL-6 and IL-8 within the subgroups according to disease duration, treatment or transfusion dependence.

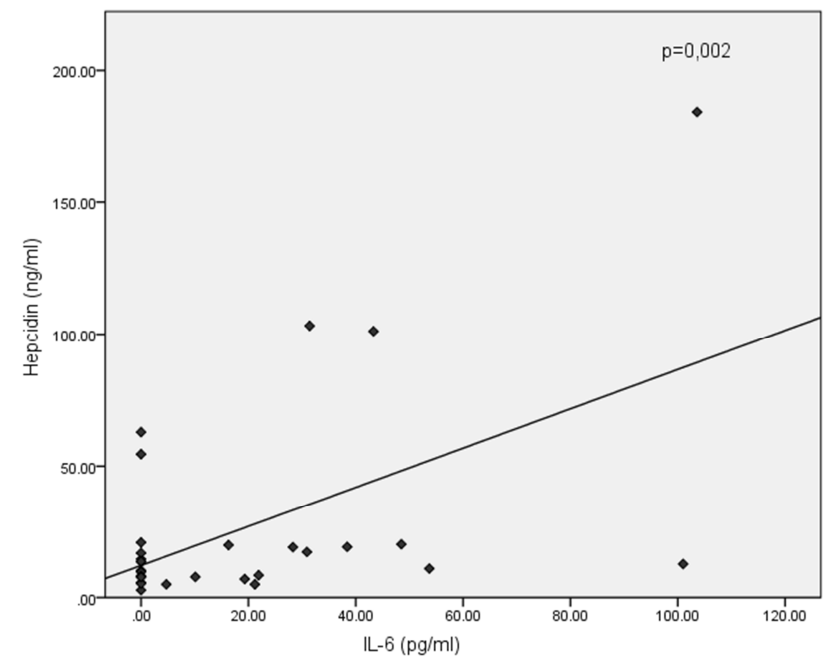

$5 \mathrm{a}$ 


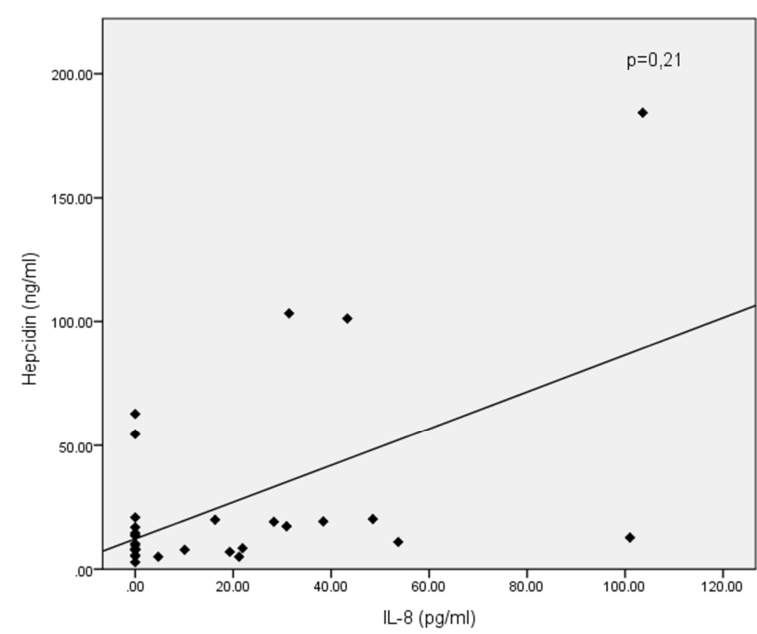

$5 b$
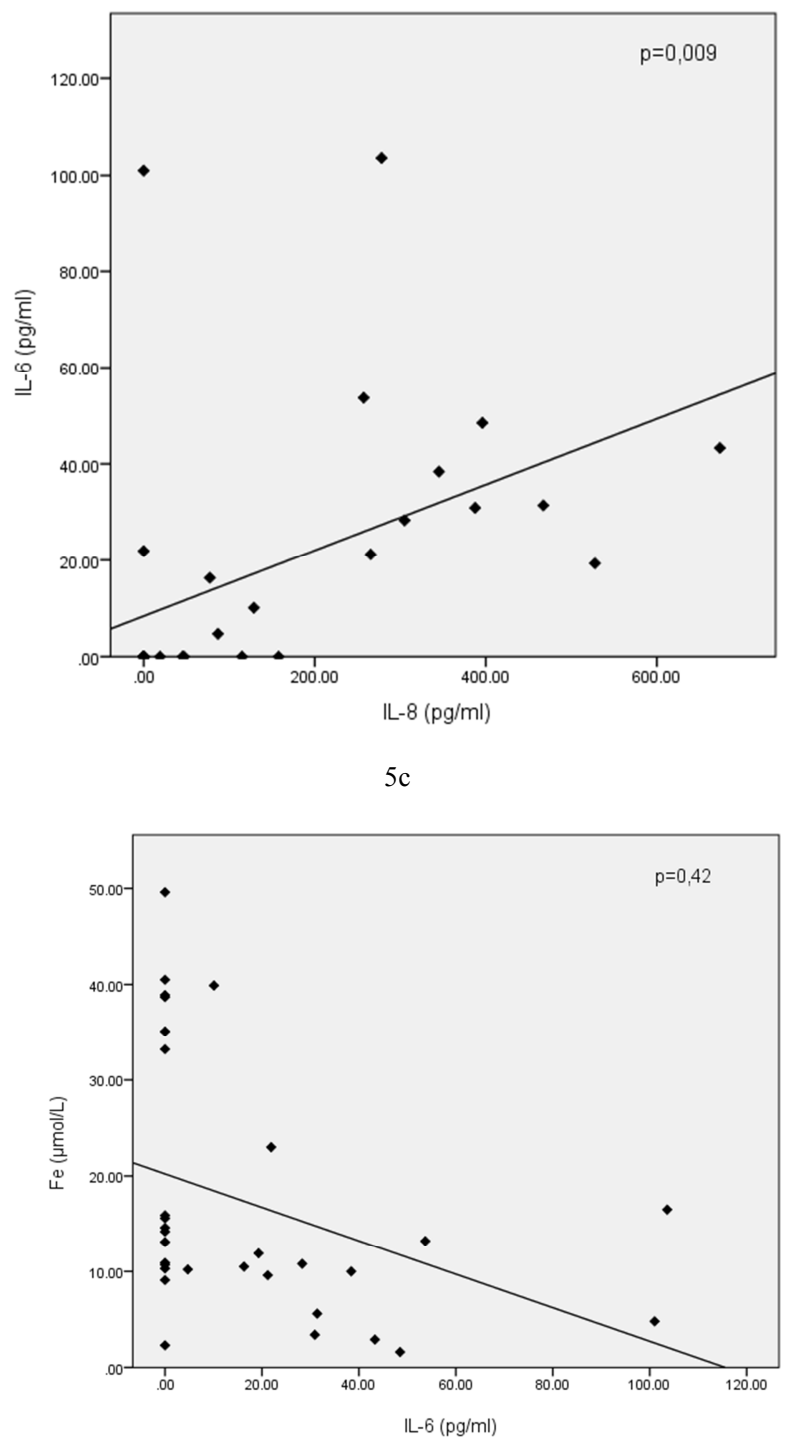

$5 \mathrm{~d}$

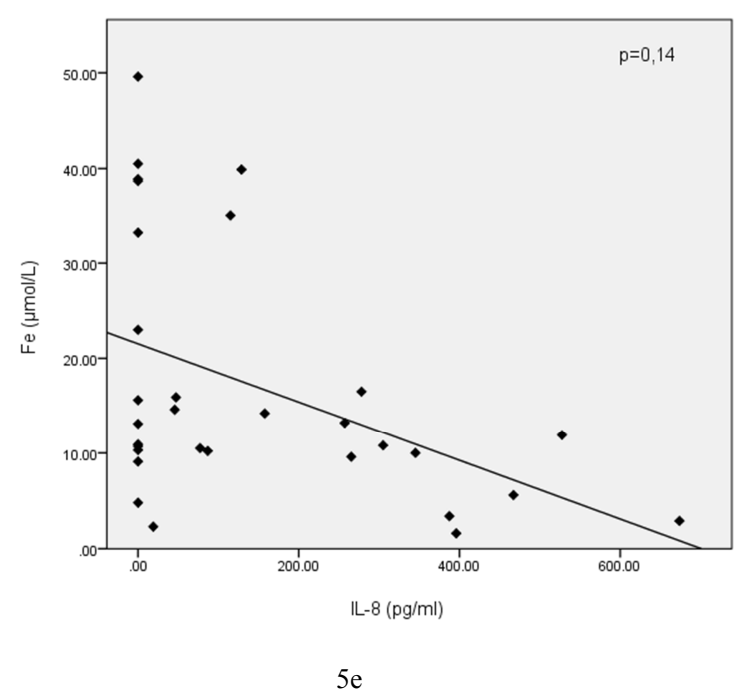

Figure 5. Correlation of hepcidin ( $\mathrm{ng} / \mathrm{ml})$ and IL-6 (pg/ml) (5a); hepcidin $(\mathrm{ng} / \mathrm{ml})$ and $\mathrm{IL}-8(\mathrm{pg} / \mathrm{ml})(5 \mathrm{~b}) ; \mathrm{IL}-6(\mathrm{pg} / \mathrm{ml})$ and $\mathrm{IL}-8(\mathrm{pg} / \mathrm{ml})(5 \mathrm{c})$; serum Fe $(\mu \mathrm{mol} / \mathrm{l})$ and $\mathrm{IL}-6(\mathrm{pg} / \mathrm{ml})(5 d)$ and serum Fe ( $\mu \mathrm{mol} / \mathrm{l})$ and $\mathrm{IL}-8(\mathrm{pg} / \mathrm{ml})(5 e)$. Linear regression plots are presented.

We explored the correlation between IL-6, IL-8, hepcidin, serum iron, ferritin and TIBC by a multivariate analysis. A significant highly positive correlation was found between hepcidin and IL-6 $(\mathrm{R}=0,535, \mathrm{p}=0,002)$ (Figure 5a) and weaker between hepcidin and IL-8 $(\mathrm{R}=0,413, \mathrm{p}=0,21)$ (Figure 5b). A significant straight correlation was demonstrated between IL- 6 and IL-8 $(\mathrm{R}=0,464, \mathrm{p}=0,009)$ (Figure $5 \mathrm{c})$ and a negative between serum iron and IL-6 $(\mathrm{R}=-$ $0,367, \mathrm{p}=0,42)$ (Figure $5 \mathrm{~d})$ and serum iron and IL-8 $(\mathrm{R}=-$ $0,438, \mathrm{p}=0,14$ ) (Figure $5 \mathrm{e}$ ).

\section{Discussion}

Based on the establishment that the iron homeostasis dysregulation is implicated in the pathogenesis of MF, we analyzed the levels of hepcidin in patients with primary and secondary MF at different time points and its correlations with circulating cytokine levels, RBC transfusions and treatment. We tried to implicate the controversary and multifactorial role of hepcidin in pathogenesis of anemia in myelofibrosis with possible impact of hepcidin upregulation in early-stage disease and in patients with no therapy.

\subsection{Hepcidin Role in Anemia Development}

Hepcidin is an important functional participator in many, but not all forms of anemia of inflammation. Hepcidinindependent mechanisms also contribute to the pathogenesis of anemia [17]. In a mouse model of anemia of aging, older mice that showed reduced hemoglobin, reduced erythrocytes and increased IL-6, were not found to demonstrate higher hepcidin. The knowledge that aged IL-6 and hepcidin knockout mice each exhibited less severe anemia suggests that both contribute to the anemia of aging [18]. In another mouse models of anemia of cancer, most models exhibited inflammation and iron-restricted erythropoiesis, but only one model had elevated hepcidin. Anemia was not improved by 
hepcidin knockout, suggesting that anemia was predominantly hepcidin-independent in some cancer models [19]. By implementing this inflammatory model to MF, we found that hepcidin separately did not correlate with the severity of anemia in the whole cohort. In severely anemic patients that require $>3 \mathrm{RBC}$ transfusions/ month, significantly lower hepcidin levels were demonstrated. Comparable results were presented in another study where hepcidin was suppressed in most of the patients with myelodysplastic syndromes and MF. Although the number of transfusions was expected to increase hepcidin excretion, in poly-transfused patients it was inappropriately low [4].

At the same time, we found significantly higher hepcidin levels in healthy controls compared to the MF group. An opposite result was presented by Pardanani et al. in a publication from 2013. The group of analyzed newly diagnosed patients with MF demonstrated higher hepcidin levels in comparison to healthy volunteers [14]. In another study, data for MDS patients revealed hepcidin levels were slightly higher than in controls, but this difference did not reach the statistical significance [20]. The discordance in the results from different studies could be an indicator that hepcidin secretion is dependent on various factors like onset of the disease, additional comorbidities or age. In combination with the highly clinical heterogeneity of the mentioned nosologic entities, it could distract the better understanding of the hepcidin impact on anemia development

We did not establish any significant correlation between higher hepcidin levels and the risk profile. A retrospective analysis of $224 \mathrm{PMF}$ patients revealed that among a list of predictive for overall and leukemia-free survival markers (circulating free light chains, inflammatory cytokines, hepcidin, ferritin, and molecular mutations) serum hepcidin was not found an independent factor for poor prognosis as well [21]. At the same time, based on a cut off level of hepcidin by ROC curve analysis for the different risk groups, we found positive correlation between higher hepcidin, leukocytosis and age in all groups which cannot be unambiguously interpreted.

We found significantly higher hepcidin levels in the patients' group with disease duration less than 1 year compared to those with disease duration between 1 to 5 years and more than 5 years. Pardanani at al. demonstrated higher hepcidin levels in newly diagnosed patients [14]. This could lead to possible interpretation of the hepcidin impact on early stage disease and basically in patients with less therapeutic intervention.

\subsection{Inflammatory Cytokines and Iron Metabolism Interaction in Anemia Development}

Hemoglobin was inversely associated with inflammatory markers, hepcidin, ferritin, reactive oxygen species and positively correlated with serum iron, transferrin, and nutritional factors [22]. Certain cytokines were involved both in immune activation/response to infection and iron transport/metabolism. Inflammation had a potent effect on decreasing serum iron levels by reducing intestinal iron absorption and sequestering iron in macrophages. All these effects were mediated by hepcidin overexpression [23]. The inflammation-triggered relationship among higher IL-6 and hepcidin levels, and lower serum iron had been shown in several studies independently of underlying cause and/or clinical characteristics of the subject of investigation. As an example, a study from 2019 compared hepcidin and IL-6 in cases with anemia of chronic disease and age-matched healthy controls. The serum hepcidin and IL-6 levels showed marked increase in cases than in controls, analogically with RBC counts, hemoglobin level and parameters of erythrocytes that were found to be significantly lower in the cases as compared to controls. Lower hemoglobin and RBC counts in cases than in controls were due to limited availability of circulating iron and reduced erythropoiesis and lower half-life of RBCs [24]. At the same time, it was known that IL-6 plays an important role in hepcidin regulation having or not any direct interaction with its role in iron metabolism and anemia development. Our results showed similarly a straight strong correlation between hepcidin and IL-6 and IL-6 and IL-8 and a weaker one between hepcidin and IL-8 with no statistically significant impact on hemoglobin, as well as a negative correlation between both IL-6 and IL-8 and serum iron in all MF patients.

\subsection{Ferritin/Hepcidin-line in Iron Metabolism Involvement in Pathogenesis of Anemia}

Ferritin is another important indicator of iron metabolism dysregulation. In a multivariate analysis of a variety of predictive markers in patients with MF, ferritin was the only independent inferior prognostic factor for survival [14]. We have previously demonstrated that in patients with PMF hemoglobin level negatively correlated with serum ferritin [25]. Ferritin as an acute-phase reactant, likely contributed to the marrow-suppressive effect of disease-related inflammation independently of iron metabolism regulation [21]. Although ferritin maintained an adverse predictive value for overall survival independently of anemia, RBC transfusions and the toxic effect of iron overload, it was supposed to sequesters excess iron, allowing iron to accumulate intracellularly while preventing iron-mediated free radical-generating reactions [5].

In the current study the levels of ferritin over the curve determined by the linear regression analysis in all risk groups positively correlated to high iron and inversely correlate to hepcidin level. The negative ferritin/hepcidin feedback could be interpreted in the context of the hepcidin role as a regulator of iron load in the background of impaired erythropoietic activity and inflammation in MF. The inappropriately low (independently of anemia) hepcidin levels correlated to iron accumulation presented by ferritin excess. Such uncertainties in hepcidin secretion could be a result of iron store variations and perhaps inflammation that led to impairment of hepcidin response to its regulators [26].

\section{Conclusion}

The hepcidin regulation is complex and multifactorial. Its role 
in pathogenesis of anemia in myelofibrosis is controversary, as many disease- and patient-related factors interfere with its regulation. Inflammation, iron overload and iron regulation distress participate in pathogenesis, clinical presentation and prognosis of MF. Their contribution is not a single step, but a complex of different mechanisms and levels of regulation which makes it complicated for an unidirectional analysis. Probably it has a higher impact in early stages of the disease and depends on treatment and transfusions. Patients with prolonged evolution, receiving regular transfusions or specific treatment, showed lower hepcidin levels. Further tests in a larger cohort of patients, could better clarify the precise mechanisms of hepcidin involvement and iron metabolism impairment in anemia in MF.

\section{Acknowledgements}

Novartis Bulgaria - research grant.

\section{References}

[1] Tefferi A, Lasho TL, Jimma T, et al. One thousand patients with primary myelofibrosis: the mayo clinic experience. Mayo Clin Proc. 2012; 87 (1): 25-33.

[2] Naymagon, Leonard; Mascarenhas, John MyelofibrosisRelated Anemia: Current and Emerging Therapeutic Strategies. HemaSphere: December 2017 - Volume 1 - Issue 1 - p e1.

[3] Nemeth, E., Tuttle, M. S., Powelson, J., Vaughn, M. B., Donovan, A., Ward, D. M., Ganz, T. \& Kaplan, J. (2004) Hepcidin regulates cellular iron efflux by binding to ferroportin and inducing its internalization. Science, 306, 2090-2093.

[4] Asher Winder, Rafi Lefkowitz, Hussam Ghoti et al. Urinary hepcidin excretion in patients with myelodysplastic syndrome and myelofibrosis. British Journal of Haematology. 2008; 142, 668-680.

[5] David H. Manz, Nicole L. Blanchette, Bibbin T. Paul, Frank M. Torti and Suzy V. Torti. Iron and cancer: recent insights Ann N Y Acad Sci. 2016 March; 1368 (1): 149-161.

[6] Alessia Pagani1, Antonella Nai1,2, Laura Silvestri1,2 and Clara Camaschella1, Hepcidin and Anemia: A Tight Relationship, MINI REVIEW ARTICLE Front. Physiol., 09 October 2019.

[7] Teasfay L., et al. Hepcidin regulation in prostate and its disruption in prostate cancer. Cancer research. 2015; 75: 22542263. [PubMed: 25858146].

[8] Zhang S. et al. Disordered hepcidin-ferroportin signaling promotes breast cancer growth. Cellular signaling. 2014; 26 : 2539-2550. [PubMed: 25093806].

[9] Goh JB, et al. Endofin, a novel BMP-SMAD regulator of the iron-regulatory hormone, hepcidin. Sci Rep. 2015; 5: 13986. [PubMed: 26358513].

[10] Guada C, Altamura S, Klein FA, at al. A novel inflammatory pathway mediating rapid hepcidin-independent hypoferremia. Blood 2015; 125: 2265-2275.
[11] Deaschemin JC, Vaulont S. Role of hepcidin in the setting of hypoferremia during acute inflammation. PLos One 2013; 8:e61050.

[12] Nairz M, Haschka D, Demetz E, Weiss G. Iron at the interface of immunity and infection. Front Pharmacol 2014; 5: 152.

[13] Weiss G. Anemia of chronic disorders: new diagnostic tools and new treatment strategies. Semin Hematol 2015; 52: 313-320.

[14] Pardanani A, Finke C, Abdelrahman RA, Lasho TL, Tefferi A. Associations and prognostic interactions between circulating levels of hepcidin, ferritin and inflammatory cytokines in primary myelofibrosis. Am J Hematol. 2013; 88 (4): 312-316. [PubMed].

[15] Barbui T, Thiele J, Gisslinger H, Finazzi G, Vannucchi AM, Tefferi A The 2016 revision of WHO classification of myeloproliferative neoplasms: Clinical and molecular advances. Blood Rev. 2016 Nov; 30 (6): 453-459. doi: 10.1016/j.blre.2016.06.001. Epub 2016 Jun 11.

[16] Passamonti F, Cervantes F, Vannucchi AM, et al. A dynamic prognostic model to predict survival in primary myelofibrosis: a study by the IWG-MRT (International Working Group for Myeloproliferative Neoplasms Research and Treatment). Blood 2010; 115 (9): 1703-1708.

[17] Chia-Yu Wang and Jodie L. Babitt. Hepcidin regulation in anemia of inflammation Curr Opin Hematol 2016, 23: 189-197.

[18] McCranor BJ, Langdon JM, Prince OD, at al. Investigation of the role of interleukin- 6 and hepcidin antimicrobial peptide in the development of anemia with age. Haematologica 2013; 98: 1633-1640.

[19] Kim A, Rivera S, Shprung D, at al. Mouse models of anemia of cancer. PLoS One 2014; 9: e93283.

[20] Santini V, Girelli D, Sanna A, Martinelli N, Duca L, et al. (2011) Hepcidin Levels and Their Determinants in Different Types of Myelodysplastic Syndromes. PLoS ONE 6 (8): e23109. doi: 10.1371/journal.pone.0023109.

[21] Animesh D. Pardanani, Terra L Lasho, Christy Finke, Ramy A. Abdelrahman, Curtis A. Hanson and Ayalew Tefferi Serum Ferritin Level At Referral Provides Independent Prognostic Information For Overall Survival In Primary Myelofibrosis. Blood 2013 122: 2824.

[22] Maccio A, Madeddu C, Gramignano G, et al. The role of inflammation, iron, and nutritional status in cancer-related anemia: results of a large, prospective, observational study. Haematologica 2014; 100: 124-132.

[23] Ganz T: Hepcidin and iron regulation, 10 years later. Blood 2011, 117: 4425-4433.

[24] Maha F. Yacoub et al. Effect of Interleukin and Hepcidin in Anemia of Chronic Diseases, Hindawi Anemia Volume 2020, Article ID 3041738, 5 pages.

[25] Liana Gercheva, Stela Dimitrova, Ilina Micheva Impact of the impaired iron homeostasis on the pathogenesis of anemia in primary myelofibrosis. Journal of IMAB -2016 , vol. 22, issue 1 .

[26] Tomas Ganz Hepcidin and iron regulation, 10 years later CA Blood (2011) 117 (17): 4425-4433. 